\title{
Increased risk of delayed cerebral ischemia in subarachnoid hemorrhage patients with additional intracerebral hematoma
}

\author{
Johannes Platz, MD, ${ }^{1}$ Erdem Güresir, MD, PhD, ${ }^{1}$ Marlies Wagner, MD, PhD, ${ }^{2}$ \\ Volker Seifert, MD, PhD, ${ }^{1}$ and Juergen Konczalla, MD'1 \\ Departments of ${ }^{1}$ Neurosurgery and ${ }^{2}$ Neuroradiology, Goethe-University Hospital, Frankfurt am Main, Germany
}

OBJECTIVE Delayed cerebral ischemia (DCI) has a major impact on the outcome of patients suffering from aneurysmal subarachnoid hemorrhage (SAH). The aim of this study was to assess the influence of an additional intracerebral hematoma (ICH) on the occurrence of DCl.

METHODS The authors conducted a single-center retrospective analysis of cases of SAH involving patients treated between 2006 and 2011. Patients who died or were transferred to another institution within 10 days after SAH without the occurrence of $\mathrm{DCl}$ were excluded from the analysis.

RESULTS Additional ICH was present in 123 (24.4\%) of 504 included patients ( $66.7 \%$ female). ICH was classified as frontal in 72 patients, temporal in 24 , and perisylvian in 27 . DCl occurred in 183 patients $(36.3 \%)$. A total of $59(32.2 \%)$ of these 183 patients presented with additional ICH, compared with $64(19.9 \%)$ of the 321 without $\mathrm{DCl}$ ( $p=0.002)$. In addition, $\mathrm{DCl}$ was detected significantly more frequently in patients with higher World Federation of Neurosurgical Societies (WFNS) grades.

The authors compared the original and modified Fisher Scales with respect to the occurrence of $\mathrm{DCl}$. The modified Fisher Scale (mFS) was superior to the original Fisher Scale (oFS) in predicting DCl. Furthermore, they suggest a new classification based on the $\mathrm{mFS}$, which demonstrates the impact of additional ICH on the occurrence of $\mathrm{DCl}$.

After the different scales were corrected for age, sex, WFNS score, and aneurysm site, the oFS no longer was predictive for the occurrence of $\mathrm{DCl}$, while the new scale demonstrated a superior capacity for prediction as compared with the $\mathrm{mFS}$.

CONCLUSIONS Additional ICH was associated with an increased risk of $\mathrm{DCl}$ in this study. Furthermore, adding the presence or absence of $\mathrm{ICH}$ to the mFS improved the identification of patients at the highest risk for the development of $\mathrm{DCl}$. Thus, a simple adjustment of the mFS might help to identify patients at high risk for $\mathrm{DCl}$.

http://thejns.org/doi/abs/10.3171/2015.12.JNS151563

KEY WORDS aneurysmal subarachnoid hemorrhage; aneurysm treatment; delayed cerebral ischemia; intracerebral hematoma; vascular disorders

$\mathrm{T}$ HE development of delayed cerebral ischemia (DCI) after aneurysmal subarachnoid hemorrhage (SAH) is the most important complication after SAH and has a severe impact on outcome for the patients. It accounts for up to $30 \%$ of new neurological deficits after the initial hemorrhage. ${ }^{20,34}$ Yet, to date, the occurrence of DCI still cannot be predicted reliably for the individual patient. Furthermore, the importance of angiographic cerebral va- sospasm (CVS) for the occurrence of DCI has recently been critically discussed. ${ }^{20,29,42}$

One of the standard methods to assess the risk of the occurrence of DCI and CVS is the scale proposed by Fisher et al. ${ }^{9}$ The scale uses 4 grades to describe the amount of subarachnoid blood evident on CT: 1, no visible subarachnoid blood; 2 , only a thin layer of subarachnoid blood or diffuse SAH; 3, a localized clot or a thick layer of sub-

ABBREVIATIONS $\mathrm{ACOA}=$ anterior communicating artery; $\mathrm{CVS}=$ cerebral vasospasm; $\mathrm{DCl}=$ delayed cerebral ischemia; $\mathrm{ICA}=$ internal carotid artery; $\mathrm{ICH}=$ intracerebral hematoma; ICP = intracranial pressure; IVH = intraventricular hemorrhage; $\mathrm{MCA}=$ middle cerebral artery; $\mathrm{mFS}=$ modified Fisher Scale; oFS = original Fisher Scale; PCoA = posterior communicating artery; $\mathrm{SAH}=$ subarachnoid hemorrhage; $\mathrm{TCD}=$ transcranial Doppler ultrasound; WFNS = World Federation of Neurosurgical Societies.

SUBMITTED July 5, 2015. ACCEPTED December 11, 2015.

INCLUDE WHEN CITING Published online March 11, 2016; DOI: 10.3171/2015.12.JNS151563. 
arachnoid blood; and 4, intraventricular or intracerebral blood with no subarachnoid blood or only diffuse or a thin layer of subarachnoid blood. The major weakness of the scale is that most of the patients are grouped into Grade 3 , which is associated with the highest risk of developing CVS. Many corrections of the original Fisher Scale (oFS) have been suggested, but only the modified Fisher Scale $(\mathrm{mFS})^{5,11}$ has been widely accepted today; most other scales are too complicated or have other flaws.

The influence of an additional intracerebral hematoma (ICH) on the occurrence of CVS and DCI is underrepresented in both the oFS and mFS. We therefore retrospectively reviewed a large number of cases involving patients treated at our center to assess whether additional ICH might represent a risk factor for the occurrence of DCI.

\section{Methods}

\section{Study Design and Inclusion and Exclusion Criteria}

Data pertaining to all patients treated at our center and suffering from aneurysmal SAH were entered into a prospectively collected database. For this study, we retrospectively reviewed cases involving patients treated between 2006 and 2011. Patients' charts and imaging data were reviewed, and the presence of ICH was assessed and stratified as described below. Imaging was reviewed in a blinded fashion. The study was approved by the local scientific and ethics review board.

Exclusion criteria were 1) patients with $\mathrm{SAH}$ due to other reasons or without aneurysms, 2) death or transfer to another hospital within 10 days after onset of SAH without the development of DCI, and 3) missing data.

\section{End Point}

Our primary end point for this study was the occurrence of DCI as detected by imaging. CT or MRI was performed in all cases $24-48$ hours after aneurysm occlusion and before discharge. DCI was defined as any new ischemic lesion on the CT or MRI before discharge compared with the imaging after aneurysm occlusion. Thus, periprocedural ischemic lesions due to securing of the aneurysm were ruled out.

\section{Classification of SAH and ICH}

Assessment of the CT scans was performed with the rater blinded to the occurrence of DCI. Additional ICH was defined as the presence of any localized parenchymal hematoma additional to the SAH. According to the location of the ICH, the patients were categorized into 3 groups for analysis (Fig. 1): 1) patients with hematomas located within the frontal lobe, 2) patients with hematomas located within the temporal lobe, and 3) patients with perisylvian hematomas. For the location of the hematoma, the imaging data were reviewed as well as operative reports, when available.

The patients were assigned oFS and mFS grades according to the blood distribution on the initial CT. For the $\mathrm{mFS}$, we used the presence of any intraventricular blood rather than biventricular hematoma as suggested by Frontera et al. ${ }^{11}$ Last, we subdivided the mFS according to the presence (+) or absence (-) of ICH at each grade.

\section{Patient Management}

After diagnosis of SAH, a digital subtraction 4-vesselangiogram was routinely performed. Hemodynamic target values included a cerebral perfusion pressure greater than $60 \mathrm{~mm} \mathrm{Hg}$ and the correction of hyponatremia and hypovolemia.

Aneurysms were treated by clipping or coiling according to the decision of an interdisciplinary neurovascular team based on the aneurysm's characteristics and the clinical condition of the patient. Hydrocephalus was treated by placement of an external ventricular drain. Early aneurysm occlusion (within 24 to 48 hours) was striven for in all cases unless the patient was hemodynamically unstable or moribund. After the aneurysm was secured, all patients were treated in the neurosurgical intensive care unit. All patients received nimodipine from the day of admission, either orally $(6 \times 60 \mathrm{mg} /$ day $)$ or intravenously $(2 \mathrm{mg} /$ hour $)$. Screening for CVS included daily clinical examination and transcranial Doppler ultrasound (TCD) measurements. If CVS was suspected clinically or on the basis of TCD, the patient underwent additional imaging studies, such as CT or MR angiography (sometimes including perfusion studies) or digital subtraction angiography.

In cases of confirmed CVS, we treated the patients with induced hypertension (mean arterial pressure $>110 \mathrm{~mm}$ $\mathrm{Hg}$ ). Endovascular treatment options for severe CVS, such as intraarterial administration of nimodipine and/or balloon dilation, were applied in selected patients.

\section{Statistical Analysis}

First, we performed a univariate analysis for the occurrence of DCI and the presence of ICH. We included various other typical risk factors: patients' sex and age (mean), WFNS (World Federation of Neurosurgical Societies) grade on admission, the site and size of the ruptured aneurysm, treatment of the ruptured aneurysm, and the amount of subarachnoid blood as defined according to the $\mathrm{oFS}$ and mFS. The chi-square-test, Fisher's exact test, and Mann-Whitney U-test were used as appropriate.

Second, we performed a multivariate analysis (logistic regression, stepwise forward, Wald model) assessing the different $\mathrm{SAH}$ rating scales. Any variables that were significant on univariate analysis, or variables considered clinically meaningful, were adjusted for in the multivariate analysis. Each CT rating scale was analyzed separately in this model. A p value $<0.05$ was considered statistically significant. All statistical analyses were performed using standard commercially available software (IBM SPSS Statistics, version 21).

\section{Results}

Between 2006 and 2011, a total of 579 patients with aneurysmal SAH were treated at our center. After exclusion of 23 patients due to missing data and 52 patients who died or were transferred before DCI would be expected to develop, 504 patients were included in this study $(66.7 \%$ of the patients were female, Table 1). An additional hematoma was found in 123 patients $(24.4 \%)$. The hematoma location was frontal in 72 patients (14.3\%), temporal in 24 patients (4.8\%) and around the sylvian fissure in 27 patients (5.4\%). 

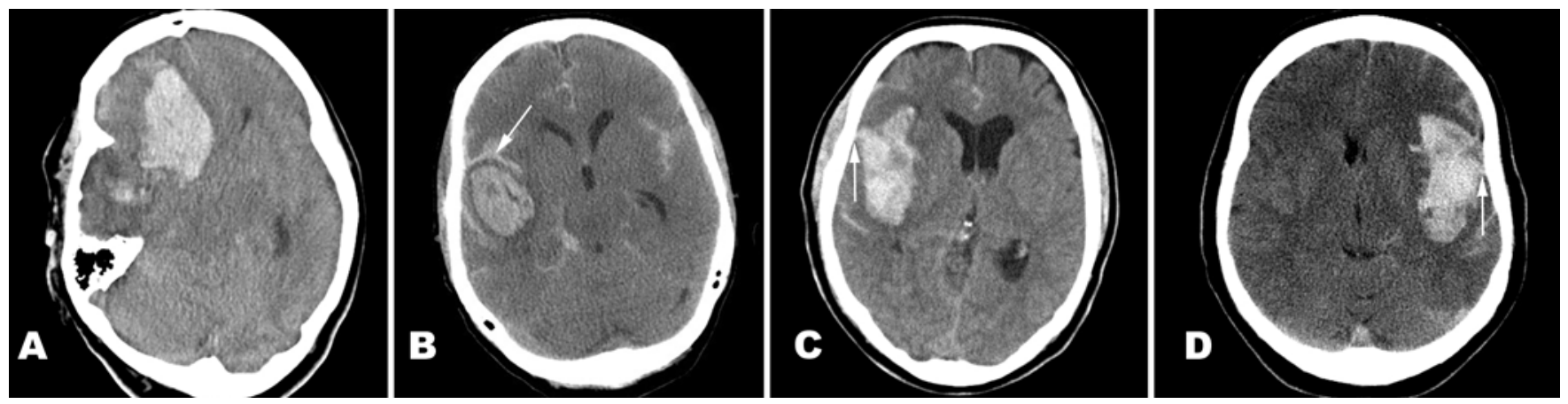

FIG. 1. Classification of ICHs. A: Large ICH within the frontal lobe. B: Example of a hematoma within the temporal lobe (note the sylvian fissure, white arrow). C and D: Perisylvian hematomas within and around the sylvian fissure. Note that these hematomas typically reach the surface at the sylvian fissure (white arrow) pushing the frontal and temporal lobes apart.

There was no significant difference in the patients' sex, their mean age, or size of the ruptured aneurysm between the groups with and without ICH (Table 1). Additional ICH was, however, more frequent in patients with higher WFNS grades and was most frequent in patients with aneurysms of the middle cerebral artery (MCA).

In all patients, the aneurysm was located most often at the anterior communicating artery (ACoA) complex (198 patients, 39.3\%), followed by aneurysms of the internal carotid artery (ICA; including aneurysms at the origin of the posterior communicating artery [PCoA], 124 patients, $24.6 \%$ ), aneurysms of the MCA (95 patients, 18.8\%) and aneurysms of the posterior circulation (87 patients, $17.2 \%$ ). In the group presenting with additional $\mathrm{ICH}, \mathrm{ICH}$ was most frequent in patients with MCA aneurysms (47.4\% of all MCA aneurysms, 45 patients), followed by aneurysms of the ACoA complex (31.3\% of all ACoA aneurysms, 62 patients), aneurysms of the ICA/PCoA (12.1\% of all ICA/ PCoA aneurysms, 15 patients) while only 1 patient with a posterior circulation aneurysm suffered from additional ICH (1.1\% of all posterior circulation aneurysms; $\mathrm{p}<$ $0.001)$.

Patients with ICH were categorized as follows using the oFS: 0 of 21 Grade 1, 1 of 64 Grade 2, 93 of 372 Grade 3 , and 29 of 47 Grade 4 . Applying the mFS, the distribution of ICH was: 0 of 21 Grade 0,19 of 79 Grade 1, 11 of 37 Grade 2, 34 of 163 Grade 3, and 59 of 204 Grade 4, respectively (Table 1$)$.

Overall, most aneurysms in this study were treated endovascularly $(314,62.3 \%)$ but in patients with additional $\mathrm{ICH}$, the rate of surgical treatment significantly increased (60 [48.8\%] of 123 patients vs 108 [28.3\%] of 381 patients without ICH, $\mathrm{p}<0.001)$. In 12 patients, the aneurysm was not occluded (because of poor admission status and/or because occlusion was technically not feasible) while in 10 patients, a combined microsurgical and endovascular approach was used.

\section{Occurrence of Delayed Ischemic Deficits}

Overall, DCI was detected in 183 patients (36.3\%, Table 2). DCI was significantly more frequent in patients with than those without ICH (59 [48.0\%] of 123 patients vs 124 [32.5\% ] of 381 patients, OR 1.911, 95\% CI 1.263-2.889, $\mathrm{p}=0.002$ ). Comparing the frequency of DCI according to
TABLE 1. Summary of patients' demographic and clinical characteristics*

\begin{tabular}{|c|c|c|c|}
\hline Parameter & $\begin{array}{c}\text { All Pts } \\
(n=504)\end{array}$ & $\begin{array}{c}\text { Pts w/ ICH } \\
(n=123)\end{array}$ & $\mathrm{p}$ Value \\
\hline Female sex & $336(66.7)$ & $77(62.6)$ & $0.271 \dagger$ \\
\hline Mean age (yrs) & $53.5 \pm 12.8$ & $54.4 \pm 11.6$ & $0.252 \ddagger$ \\
\hline Aneurysm location & & & $<0.001 \S$ \\
\hline $\mathrm{ACOA}$ & 198 & 62 & \\
\hline ICA/PCoA & 124 & 15 & \\
\hline MCA & 95 & 45 & \\
\hline Pst circulation & 87 & 1 & \\
\hline Mean aneurysm size (mm) & $6.9 \pm 3.5$ & $7.1 \pm 3.4$ & $0.172 \ddagger$ \\
\hline WFNS grade on admission & & & $<0.001 \dagger$ \\
\hline 1 & $175(34.7)$ & $18(14.6)$ & \\
\hline 2 & $73(14.5)$ & $18(14.6)$ & \\
\hline 3 & $52(10.3)$ & $10(8.1)$ & \\
\hline 4 & $53(10.5)$ & $21(17.1)$ & \\
\hline 5 & $151(29.7)$ & $56(45.5)$ & \\
\hline Original Fisher Scale & & & $<0.001 \S$ \\
\hline 1 & $21(4.2)$ & $0(0)$ & \\
\hline 2 & $64(12.7)$ & $1(0.8)$ & \\
\hline 3 & $372(73.8)$ & $93(75.6)$ & \\
\hline 4 & $47(9.3)$ & $29(23.6)$ & \\
\hline Modified Fisher Scale & & & $0.012 \S$ \\
\hline 0 & $21(4.2)$ & $0(0)$ & \\
\hline 1 & $79(15.7)$ & $19(15.4)$ & \\
\hline 2 & $37(7.3)$ & $11(8.9)$ & \\
\hline 3 & $163(32.3)$ & $34(27.6)$ & \\
\hline 4 & $204(40.5)$ & $59(48.0)$ & \\
\hline Aneurysm treatment & & & $<0.001 \S$ \\
\hline No occlusion & 12 & 6 & \\
\hline Clipping & 168 & 60 & \\
\hline Coiling & 314 & 54 & \\
\hline Combined occlusion & 10 & 3 & \\
\hline
\end{tabular}

Pst $=$ posterior; Pts $=$ patients.

* Values represent numbers of patients (\%) unless otherwise indicated. Mean values are presented with standard deviations. Boldface type indicates statistical significance.

$\dagger$ Chi-square test.

$\ddagger$ Mann-Whitney U-test.

$\S$ Fisher's exact-test. 
TABLE 2. Univariate analysis of the occurrence of $\mathrm{DCl}^{*}$

\begin{tabular}{|c|c|c|c|}
\hline Parameter & $\begin{array}{l}\text { No DCl }(n= \\
321[63.7 \%])\end{array}$ & $\begin{array}{c}\mathrm{DCl}(\mathrm{n}=183 \\
[36.3 \%])\end{array}$ & $p$ Value \\
\hline Mean age (yrs) & $53.1 \pm 13.0$ & $54.2 \pm 12.5$ & $0.510 \dagger$ \\
\hline Female sex & $202(62.9)$ & $134(73.2)$ & $0.018 \ddagger$ \\
\hline WFNS grade on admission & & & $<0.001 \ddagger$ \\
\hline 1 & 137 & 38 & \\
\hline 2 & 45 & 28 & \\
\hline 3 & 28 & 24 & \\
\hline 4 & 28 & 25 & \\
\hline 5 & 83 & 68 & \\
\hline Additional ICH & $64(19.9)$ & $59(32.2)$ & $0.002 \ddagger$ \\
\hline Location of ICH & & & $0.019 \ddagger$ \\
\hline Frontal & 39 (12.1) & $33(18.0)$ & \\
\hline Temporal & $12(3.7)$ & $12(6.6)$ & \\
\hline Perisylvian & $13(4.0)$ & $14(7.7)$ & \\
\hline $\begin{array}{l}\text { Mean aneurysm size } \\
\quad(\mathrm{mm})\end{array}$ & $6.9 \pm 3.6$ & $6.8 \pm 3.5$ & $0.730 \dagger$ \\
\hline Aneurysm site & & & $0.024 \ddagger$ \\
\hline $\mathrm{ACOA}$ & $126(39.3)$ & $72(39.3)$ & \\
\hline ICA incl PCoA & $83(25.9)$ & $41(22.4)$ & \\
\hline MCA & $49(15.3)$ & $46(25.1)$ & \\
\hline Pst circulation & $63(19.6)$ & $24(13.1)$ & \\
\hline Aneurysm treatment & & & $0.101 \S$ \\
\hline No successful occlusion & $8(2.5)$ & $4(2.2)$ & \\
\hline Clipping & $98(30.5)$ & $70(38.3)$ & \\
\hline Coiling & $211(65.7)$ & $103(56.3)$ & \\
\hline Combined occlusion & $4(1.2)$ & $6(3.3)$ & \\
\hline \multicolumn{4}{|c|}{$\begin{array}{l}\text { Incl }=\text { including. } \\
\text { * Values represent numbers of patients }(\%) \text { unless otherwise indicated. Mean } \\
\text { values are presented with standard deviations. Boldface type indicates statisti- } \\
\text { cal significance. } \\
\dagger \text { Mann-Whitney U-test. } \\
\text { † Chi-square test. } \\
\text { § Fisher's exact-test. }\end{array}$} \\
\hline
\end{tabular}

the location of $\mathrm{ICH}$, we found that perisylvian hematomas were most often associated with DCI (51.9\%), followed by temporal $(50.0 \%)$ and frontal hematomas $(45.8 \%, \mathrm{p}=$ 0.019).

Furthermore, DCI occurred more frequently in patients with higher WFNS grades $(\mathrm{p}<0.001)$ and in female patients $(\mathrm{p}=0.018)$. In patients with DCI, the ruptured aneurysm was most often located at the MCA (48.4\% of all MCA aneurysms, $p=0.024$ ). There was no significant difference in the frequency of DCI according to the patients' mean age $(p=0.510)$, the mean aneurysm size $(p=0.730)$, or aneurysm treatment $(\mathrm{p}=0.101)$.

\section{Assessment of the Different CT Rating Scales and the Occurrence of DCl}

According to the oFS, 2 of 21 patients with Grade 1, 14 of 64 with Grade 2, 151 of 372 with Grade 3, and 16 of 47 patients with Grade 4 SAH developed DCI $(\mathrm{p}=0.002$, Table 3). Applying the mFS, DCI was detected in 2 of 21 patients with Grade 0, 18 of 79 patients with Grade 1, 10 of 37 patients with Grade 2, 60 of 163 patients with Grade 3 , and 93 of 204 patients with Grade 4 SAH ( $<0.001)$.
In both scales, the risk of developing DCI varied significantly.

We then tested whether the additional rating of ICH in the $\mathrm{mFS}$ results in a further improvement in the prediction of DCI. As shown in Table 3, patients with ICH in this classification of the $\mathrm{mFS}$ in general have a higher risk of developing ICH than the corresponding patients without $\mathrm{ICH}$. Furthermore, there is a rather continuous increase in the OR for development of DCI rising from Grade 0 to $4+$.

Finally, we tested the predictive value of the different CT grading scales for the occurrence of DCI in a multivariate model and adjusted for the patients' age, sex, WFNS grade at admission, and aneurysm location (Table 3). After adjustment for these factors, the oFS no longer was an independent predictor of the occurrence of DCI, while the mFS just barely retained its significance $(p=$ $0.046)$. In contrast, the mFS including ICH grading was a highly significant independent predictor $(\mathrm{p}=0.018)$, and patients with a Grade 4+ had an almost 10-fold increased risk of developing DCI compared with patients with a Grade 0 SAH. Again, patients with ICH almost always had a higher risk of developing DCI than the patients without ICH in the same grade.

\section{Discussion}

The classification of the amount and distribution of subarachnoid blood originally suggested by Fisher et al. has been widely accepted in the neurosurgical community for assessing the risk of the occurrence of vasospasm..$^{9}$ This original Fisher Scale (oFS) was revised in 2001 and 2006 and since then, the modified Fisher Scale (mFS) has been used routinely. ${ }^{5,11}$ Nevertheless, the presence and effect of additional ICHs is underrepresented in both classifications. In this study, we demonstrate that additional ICH may represent an important risk factor for the occurrence of DCI.

We chose the end point "occurrence of DCI" rather than "CVS" for various reasons. First, it seems more reliable to determine the presence of DCI based on identification of any new ischemic lesions, after ruling out procedure-related infarctions due to securing of the aneurysm, as this method relies on objective imaging data. Second, the definition of CVS is controversial and its detection is even more complicated. ${ }^{29,34}$ As the neurological status of many SAH patients cannot be assessed reliably due to a decreased level of consciousness, clinical deterioration may easily be missed as a sign of CVS. This is especially true in patients with additional ICH, whose status is often poor at admission. ${ }^{34}$

Since the introduction of the original scale by Fisher et al., various modifications have been suggested to improve the predictability of DCI and the use of the scale in daily clinical practice. $5,10,11,14,16,19,23,25,27,28,32,37$ Yet, to date the oFS and mFS are still most widely used despite their weaknesses. The main flaws of the oFS are 1) its nonlinear character, with a decrease in the risk of vasospasm from Grade 3 to Grade $4 ; 2$ ) its moderate interobserver reliability; ${ }^{38}$ and 3) the manner in which intraventricular hemorrhage (IVH) and ICH are handled. On the other hand, most new scales are too complex for daily use or are focused on the presence of IVH, as the mFS. $11,18,19,31,32,35,38,40,41$ 
TABLE 3. Analysis of the different CT grading scales

\begin{tabular}{|c|c|c|c|c|}
\hline Parameter & No DCl $(n=321)$ & $\mathrm{DCl}(\mathrm{n}=183)$ & Crude OR (95\% Cl) & Adjusted OR* $(95 \% \mathrm{Cl})$ \\
\hline \multicolumn{5}{|l|}{ Original Fisher Scale } \\
\hline Grade 1 & $19(90 \%)$ & $2(10 \%)$ & - & - \\
\hline Grade 2 & $50(78 \%)$ & $14(22 \%)$ & $2.660(0.552-12.823)$ & - \\
\hline Grade 3 & $221(59 \%)$ & $151(41 \%)$ & $6.491(1.490-28.277)$ & - \\
\hline Grade 4 & $31(66 \%)$ & $16(34 \%)$ & $4.903(1.013-23.734)$ & - \\
\hline$p$ for trend $\left(R^{2}\right)$ & & & 0.001 & $0.126(0.111)$ \\
\hline \multicolumn{5}{|l|}{ Modified Fisher Scale } \\
\hline Grade 0 & $19(90 \%)$ & $2(10 \%)$ & - & - \\
\hline Grade 1 & $61(77 \%)$ & $18(23 \%)$ & $2.803(0.596-13.194)$ & $2.178(0.443-10.698)$ \\
\hline Grade 2 & $27(73 \%)$ & $10(27 \%)$ & $3.519(0.691-17.916)$ & $2.581(0.478-13.942)$ \\
\hline Grade 3 & $103(63 \%)$ & $60(37 \%)$ & $5.534(1.245-24.589)$ & $3.904(0.839-18.168)$ \\
\hline Grade 4 & $111(54 \%)$ & $93(46 \%)$ & $7.959(1.807-35.065)$ & $4.852(1.030-22.859)$ \\
\hline$p$ for trend $\left(R^{2}\right)$ & & & $<0.001$ & $0.046(0.138)$ \\
\hline \multicolumn{5}{|c|}{ Modified Fisher Scale incl ICH† } \\
\hline Grade 0 & $19(90 \%)$ & $2(10 \%)$ & - & - \\
\hline Grade 1 & $48(80 \%)$ & $12(20 \%)$ & $2.375(0.485-11.628)$ & $2.321(0.466-11.556)$ \\
\hline Grade 1+ & $13(68 \%$ & $6(32 \%)$ & $4.385(0.763-25.204)$ & $2.998(0.500-17.974)$ \\
\hline Grade 2 & $21(81 \%)$ & $5(19 \%)$ & $2.262(0.392-13.060)$ & $1.714(0.288-10.213)$ \\
\hline Grade 2+ & $6(54 \%)$ & $5(46 \%)$ & 7.917 (1.209-51.841) & $5.335(0.762-37.329)$ \\
\hline Grade 3 & $81(63 \%)$ & $48(37 \%)$ & $5.630(1.256-25.233)$ & $4.656(1.018-21.300)$ \\
\hline Grade 3+ & $22(65 \%)$ & $12(35 \%)$ & $5.182(1.028-26.130)$ & $3.735(0.709-19.663)$ \\
\hline Grade 4 & $88(61 \%)$ & $57(39 \%)$ & $6.153(1.380-27.430)$ & $3.890(0.835-18.118)$ \\
\hline Grade 4+ & $36(61 \%)$ & $23(39 \%)$ & $14.870(3.162-69.925)$ & $9.264(1.874-45.803)$ \\
\hline$p$ for trend $\left(R^{2}\right)$ & & & $<0.001$ & $0.018(0.137)$ \\
\hline
\end{tabular}

* Adjusted for age, sex, WFNS grade, and aneurysm location.

$\dagger$ In the modified Fisher Scale including ICH, "+" represents the patients with additional ICH.

There are some additional problems with the mFS as well. First, it has been developed and tested only in patients after surgical aneurysm repair. Endovascularly treated patients, who are in the majority today in most centers, were not considered in the development of the mFS. ${ }^{5,11}$ Furthermore, the developers of the mFS focused on the impact of IVH on the development of "symptomatic vasospasm." We think that the definition of "symptomatic vasospasm" as used then might no longer be accurate, as the concept of DCI has shifted with the impact of angiographic vasospasm diminishing. ${ }^{20,29,34,42}$ As an objective outcome parameter, DCI seems more suitable than "clinical vasospasm," which was often used in older studies and defined by clinical deterioration otherwise unexplained but which did not have to lead to delayed ischemia.

Whereas Claassen et al. ${ }^{5}$ originally suggested classifying IVH as positive in patients with hemorrhage in both lateral ventricles only, Frontera et al..$^{11}$ rated IVH positive if there was blood in any ventricle. This created some uncertainty regarding the definition of IVH in the mFS, as large unilateral IVH could be regarded as "no IVH" using the definition of Claassen et al.

In the present study, we demonstrate that the mFS not only is valid for endovascularly treated patients but also remains valid with the more modern end point, "occurrence of DCI."

Although the impact of ICH on treatment and outcome of SAH has been studied often, ${ }^{1,4,7,12,13,15,24,26-28,33,39}$ data on the prediction of DCI due to ICH are very limited..$^{12}$ The presence of ICH was not assessed in detail in the mFS. Crobeddu et al. ${ }^{6}$ found an association of ICH with the development of DCI on the univariate analysis, but it was not significant in the multivariate analysis.

As the occurrence of DCI is thought to be correlated with the amount of subarachnoid blood and its degradation products, $, 3,3,5,16,17,21,22$ it seems reasonable that patients with additional ICH and hence more intracranial blood would be at a higher risk of developing DCI. One important difference in patients with isolated ICH, in whom DCI almost never occurs, might be that due to the underlying aneurysmal SAH, there usually is a readily accessible connection of the hematoma to the subarachnoid space. Thus, degradation products might increase not only the local risk of DCI but also the general risk of DCI, by an increased washout of degradation products into the subarachnoid space. As it was shown earlier that the odds of vasospasm decreased with an increase of the clearance rate of subarachnoid blood and the initial clot volume, ${ }^{30}$ the reverse mechanism seems likely in the presence of ICH.

This hypothesis emphasizes the role of hematomas located within the sylvian fissure and thus within the subarachnoid space directly. In the present study, perisylvian hematomas showed the highest risk of DCI (occurring in $51.9 \%$ of perisylvian hematomas), while frontal hematomas had the lowest risk of DCI (45.8\%, Table 2). Additional ICH was most frequent in patients with MCA aneurysms, which usually result in perisylvian or temporal hematomas. Although we did not assess hematoma volume 
in this study, hematomas caused by MCA aneurysms are often larger than those seen in ruptured ACoA aneurysms. One other study found an increased risk of CVS in sylvian fissure hematomas compared with subpial hematomas due to ruptured MCA aneurysms. ${ }^{33}$

Another mechanism resulting in a higher rate of DCI in patients with additional ICH might be a more severe early brain injury. ${ }^{36}$ The additional volume of the hematoma itself might easily explain a higher initial peak and longer sustained increase in intracranial pressure (ICP) than in patients without ICH. Elevated ICP may be correlated with the extent of early brain injury, which may itself contribute severely to the occurrence of DCI.

As the adjusted mFS (the mFS including ICH) had the highest significance after adjustment for possible confounders in this study, the importance of additional ICH to predict DCI is underlined. Yet, again, we cannot distinguish whether this is due to the increased amount of blood or an increased early brain injury or both.

For a better assessment of the risk for the patient of the occurrence of DCI, an easy modification of the Fisher scale may be performed: the presence of ICH could be marked by "+" and the absence of ICH with "-", thus allowing better identification of high-risk patients.

\section{Limitations of the Study}

First, this study is retrospective, thus the typical limitations, such as selection bias, bias due to missing data, and lack of randomization, apply. To partly address the issue of selection bias, the rater was blinded to the occurrence of DCI when quantifying the CT scans. Furthermore, we did not consider hematoma size. Yet, for daily practice, it seems best to distinguish only between patients with and those without hematoma. If one were to consider hematoma size, the assessment would be a lot more complicated, and the scale would have to be more complex as well. As complex scales are often regarded as cumbersome, their use in daily practice is limited.

Last, there is an ongoing debate on the correct time point for grading the amount of subarachnoid blood. Due to the clearance of the brain, the blood is washed out soon after the hemorrhage. Therefore, various groups have suggested different time windows for the grading, which might have to be as early as within the first 24 hours. ${ }^{8}$ In this study, we did not analyze the timing of the CT, which was used for grading. On the other hand, wash-out of localized hematomas usually takes longer than that of subarachnoid blood.

As this is a retrospective single-center study, these findings need prospective validation in independent cohorts before they can reliably applied in practice.

\section{Conclusions}

In this study, we demonstrate that additional ICH increases the risk of DCI after SAH. Futhermore, we confirm for the first time that the mFS holds true in predicting DCI in endovasculary treated SAH patients. A simple modification of the $\mathrm{mFS}$ incorporates the additional risk of ICH and helps to improve the identification of patients with the highest risk of DCI. This risk seems to be greatest in cases of perisylvian hematomas, where the blood and its degradation products are located within the subarachnoid space in close proximity to major vessels. Whether the blood itself or a more severe early brain injury is the underlying mechanism for this increased risk of DCI remains unclear. Of course, for future validation, prospective studies are warranted.

\section{Acknowledgments}

We thank Prof. Eva Herrmann and Dr. Natalie Filmann of the Institute of Biostatistics and Mathematical Modeling for support with data analysis.

\section{References}

1. Abbed KM, Ogilvy CS: Intracerebral hematoma from aneurysm rupture. Neurosurg Focus 15(4):E4, 2003

2. Adams HP Jr, Kassell NF, Torner JC, Haley EC Jr: Predicting cerebral ischemia after aneurysmal subarachnoid hemorrhage: influences of clinical condition, CT results, and antifibrinolytic therapy. A report of the Cooperative Aneurysm Study. Neurology 37:1586-1591, 1987

3. Brouwers PJ, Dippel DW, Vermeulen M, Lindsay KW, Hasan D, van Gijn J: Amount of blood on computed tomography as an independent predictor after aneurysm rupture. Stroke 24:809-814, 1993

4. Bruder M, Schuss P, Berkefeld J, Wagner M, Vatter H, Seifert $\mathrm{V}$, et al: Subarachnoid hemorrhage and intracerebral hematoma caused by aneurysms of the anterior circulation: influence of hematoma localization on outcome. Neurosurg Rev 37:653-659, 2014

5. Claassen J, Bernardini GL, Kreiter K, Bates J, Du YE, Copeland D, et al: Effect of cisternal and ventricular blood on risk of delayed cerebral ischemia after subarachnoid hemorrhage: the Fisher scale revisited. Stroke 32:2012-2020, 2001

6. Crobeddu E, Mittal MK, Dupont S, Wijdicks EF, Lanzino G, Rabinstein AA: Predicting the lack of development of delayed cerebral ischemia after aneurysmal subarachnoid hemorrhage. Stroke 43:697-701, 2012

7. de los Reyes K, Patel A, Bederson JB, Frontera JA: Management of subarachnoid hemorrhage with intracerebral hematoma: clipping and clot evacuation versus coil embolization followed by clot evacuation. J Neurointerv Surg 5:99-103, 2013

8. Dupont SA, Wijdicks EF, Manno EM, Lanzino G, Brown RD Jr, Rabinstein AA: Timing of computed tomography and prediction of vasospasm after aneurysmal subarachnoid hemorrhage. Neurocrit Care 11:71-75, 2009

9. Fisher CM, Kistler JP, Davis JM: Relation of cerebral vasospasm to subarachnoid hemorrhage visualized by computerized tomographic scanning. Neurosurgery 6:1-9, 1980

10. Friedman JA, Goerss SJ, Meyer FB, Piepgras DG, Pichelmann MA, McIver JI, et al: Volumetric quantification of Fisher Grade 3 aneurysmal subarachnoid hemorrhage: a novel method to predict symptomatic vasospasm on admission computerized tomography scans. J Neurosurg 97:401-407, 2002

11. Frontera JA, Claassen J, Schmidt JM, Wartenberg KE, Temes $\mathrm{R}$, Connolly ES Jr, et al: Prediction of symptomatic vasospasm after subarachnoid hemorrhage: the modified fisher scale. Neurosurgery 59:21-27, 2006

12. Graham DI, Macpherson P, Pitts LH: Correlation between angiographic vasospasm, hematoma, and ischemic brain damage following SAH. J Neurosurg 59:223-230, 1983

13. Güresir E, Beck J, Vatter H, Setzer M, Gerlach R, Seifert V, et al: Subarachnoid hemorrhage and intracerebral hematoma: incidence, prognostic factors, and outcome. Neurosurgery 63:1088-1094, 2008 
14. Gurusinghe NT, Richardson AE: The value of computerized tomography in aneurysmal subarachnoid hemorrhage. The concept of the CT score. J Neurosurg 60:763-770, 1984

15. Hauerberg J, Eskesen V, Rosenørn J: The prognostic significance of intracerebral haematoma as shown on CT scanning after aneurysmal subarachnoid haemorrhage. Br J Neurosurg 8:333-339, 1994

16. Hijdra A, Brouwers PJ, Vermeulen M, van Gijn J: Grading the amount of blood on computed tomograms after subarachnoid hemorrhage. Stroke 21:1156-1161, 1990

17. Kistler JP, Crowell RM, Davis KR, Heros R, Ojemann RG, Zervas $\mathrm{T}$, et al: The relation of cerebral vasospasm to the extent and location of subarachnoid blood visualized by CT scan: a prospective study. Neurology 33:424-436, 1983

18. Ko SB, Choi HA, Carpenter AM, Helbok R, Schmidt JM, Badjatia N, et al: Quantitative analysis of hemorrhage volume for predicting delayed cerebral ischemia after subarachnoid hemorrhage. Stroke 42:669-674, 2011

19. Kramer AH, Mikolaenko I, Deis N, Dumont AS, Kassell NF, Bleck TP, et al: Intraventricular hemorrhage volume predicts poor outcomes but not delayed ischemic neurological deficits among patients with ruptured cerebral aneurysms. Neurosurgery 67:1044-1053, 2010

20. Macdonald RL: Delayed neurological deterioration after subarachnoid haemorrhage. Nat Rev Neurol 10:44-58, 2014

21. Macdonald RL, Weir BK: A review of hemoglobin and the pathogenesis of cerebral vasospasm. Stroke 22:971-982, 1991

22. Mayberg MR: Cerebral vasospasm. Neurosurg Clin N Am 9:615-627, 1998

23. Mohsen F, Pomonis S, Illingworth R: Prediction of delayed cerebral ischaemia after subarachnoid haemorrhage by computed tomography. J Neurol Neurosurg Psychiatry 47:1197-1202, 1984

24. Nakagawa T, Suga S, Mayanagi K, Akaji K, Inamasu J, Kawase T: Predicting the overall management outcome in patients with a subarachnoid hemorrhage accompanied by a massive intracerebral or full-packed intraventricular hemorrhage: a 15-year retrospective study. Surg Neurol 63:329335,2005

25. Nomura Y, Kawaguchi M, Yoshitani K, Kurita N, Hayashi H, Tamura K, et al: Retrospective analysis of predictors of cerebral vasospasm after ruptured cerebral aneurysm surgery: influence of the location of subarachnoid blood. J Anesth 24:1-6, 2010

26. Nowak G, Schwachenwald D, Schwachenwald R, Kehler U, Müller H, Arnold H: Intracerebral hematomas caused by aneurysm rupture. Experience with 67 cases. Neurosurg Rev 21:5-9, 1998

27. Papo I, Bodosi M, Doczi T: Intracerebral haematomas from aneurysm rupture: their clinical significance. Acta Neurochir (Wien) 89:100-105, 1987

28. Pasqualin A, Bazzan A, Cavazzani P, Scienza R, Licata C, Da Pian R: Intracranial hematomas following aneurysmal rupture: experience with 309 cases. Surg Neurol 25:6-17, 1986

29. Pluta RM, Hansen-Schwartz J, Dreier J, Vajkoczy P, Macdonald RL, Nishizawa S, et al: Cerebral vasospasm following subarachnoid hemorrhage: time for a new world of thought. Neurol Res 31:151-158, 2009

30. Reilly C, Amidei C, Tolentino J, Jahromi BS, Macdonald RL: Clot volume and clearance rate as independent predictors of vasospasm after aneurysmal subarachnoid hemorrhage. J Neurosurg 101:255-261, 2004

31. Rosen DS, Macdonald RL: Subarachnoid hemorrhage grading scales: a systematic review. Neurocrit Care 2:110-118, 2005

32. Rosen DS, Macdonald RL, Huo D, Goldenberg FD, Novakovic RL, Frank JI, et al: Intraventricular hemorrhage from ruptured aneurysm: clinical characteristics, complications, and outcomes in a large, prospective, multicenter study population. J Neurosurg 107:261-265, 2007

33. Saito A, Akamatsu Y, Mikawa S, Sugawara T, Seki H: Comparison of large intrasylvian and subpial hematomas caused by rupture of middle cerebral artery aneurysm. Neurol Med Chir (Tokyo) 50:281-285, 2010

34. Sarrafzadeh AS, Vajkoczy P, Bijlenga P, Schaller K: Monitoring in neurointensive care-the challenge to detect delayed cerebral ischemia in high-grade aneurysmal SAH. Front Neurol 5:134, 2014

35. Schaller C, Rohde V, Meyer B, Hassler W: Amount of subarachnoid blood and vasospasm: current aspects. A transcranial Doppler study. Acta Neurochir (Wien) 136:67-71, 1995

36. Sehba FA, Pluta RM, Zhang JH: Metamorphosis of subarachnoid hemorrhage research: from delayed vasospasm to early brain injury. Mol Neurobiol 43:27-40, 2011

37. Smith ML, Abrahams JM, Chandela S, Smith MJ, Hurst RW, Le Roux PD: Subarachnoid hemorrhage on computed tomography scanning and the development of cerebral vasospasm: the Fisher grade revisited. Surg Neurol 63:229-235, 2005

38. Svensson E, Starmark JE, Ekholm S, von Essen C, Johansson A: Analysis of interobserver disagreement in the assessment of subarachnoid blood and acute hydrocephalus on CT scans. Neurol Res 18:487-494, 1996

39. Tapaninaho A, Hernesniemi J, Vapalahti M: Emergency treatment of cerebral aneurysms with large haematomas. Acta Neurochir (Wien) 91:21-24, 1988

40. van der Jagt M, Hasan D, Bijvoet HW, Pieterman H, Koudstaal PJ, Avezaat CJ: Interobserver variability of cisternal blood on CT after aneurysmal subarachnoid hemorrhage. Neurology 54:2156-2158, 2000

41. van Norden AG, van Dijk GW, van Huizen MD, Algra A, Rinkel GJ: Interobserver agreement and predictive value for outcome of two rating scales for the amount of extravasated blood after aneurysmal subarachnoid haemorrhage. J Neurol 253:1217-1220, 2006

42. Wagner M, Steinbeis P, Güresir E, Hattingen E, du Mesnil de Rochemont R, Weidauer S, et al: Beyond delayed cerebral vasospasm: infarct patterns in patients with subarachnoid hemorrhage. Clin Neuroradiol 23:87-95, 2013

\section{Disclosures}

The authors report no conflict of interest concerning the materials or methods used in this study or the findings specified in this paper.

\section{Supplemental Information \\ Previous Presentations}

Parts of this study were presented as an abstract at the 64th Annual Meeting of the German Neurosurgical Society, May 29, 2013 , in Düsseldorf.

\section{Author Contributions}

Conception and design: Platz. Acquisition of data: Platz, Güresir, Wagner. Analysis and interpretation of data: Platz, Wagner, Konczalla. Drafting the article: Platz. Critically revising the article: Wagner, Seifert, Konczalla. Reviewed submitted version of manuscript: Seifert, Konczalla. Approved the final version of the manuscript on behalf of all authors: Platz. Statistical analysis: Platz. Study supervision: Seifert.

\section{Correspondence}

Johannes Platz, Department of Neurosurgery, Goethe-University Hospital, Schleusenweg 2-16, Frankfurt am Main D-60528, Germany.email: platz@med.uni-frankfurt.de. 